http://doi.org/10.35784/iapgos.912

\title{
INVESTIGATION OF THE KOLMOGOROV-WIENER FILTER FOR CONTINUOUS FRACTAL PROCESSES ON THE BASIS OF THE CHEBYSHEV POLYNOMIALS OF THE FIRST KIND
}

\author{
Vyacheslav Gorev, Alexander Gusev, Valerii Korniienko \\ Dnipro University of Technology, Department of Information Security and Telecommunications, Dnipro, Ukraine
}

\begin{abstract}
This paper is devoted to the investigation of the Kolmogorov-Wiener filter weight function for continuous fractal processes with a power-law structure function. The corresponding weight function is sought as an approximate solution to the Wiener-Hopf integral equation. The truncated polynomial expansion method is used. The solution is obtained on the basis of the Chebyshev polynomials of the first kind. The results are compared with the results of the authors' previous investigations devoted to the same problem where other polynomial sets were used. It is shown that different polynomial sets present almost the same behaviour of the solution convergence.
\end{abstract}

Keywords: continuous fractal processes, Kolmogorov-Wiener filter weight function, Chebyshev polynomials of the first kind

\section{BADANIE FILTRU KOLMOGOROWA-WIENERA DLA CIAGGLYCH PROCESÓW FRAKTALNYCH W OPARCIU O WIELOMIANY CZYBYSZEWA PIERWSZEGO RODZAJU}

Streszczenie. Praca ta jest poświęcona badaniu wagi filtra Kotmogorowa-Wienera dla ciagtych procesów fraktalnych w oparciu o funkcje gęstości prawdopodobieństwa. Glównym zamierzeniem jest znalezienie odpowiedniej wagi będacej przybliżonym rozwiązaniem równania całkowego WieneraHopfa. W tym celu wykorzystano metode rozwiniecia ograniczonego wielomianu. Rozwiazanie oparte jest na wielomianach Czybyszewa pierwszego rodzaju. Wyniki sa porównywane z wcześniejszymi badaniami autora dotyczacymi tego samego problemu, w których to użyte zostały inne układy wielomianów. Udowodniono, że różne układy wielomianów zachowuja się podobnie a ich rozwiąania sa zbieżne.

Slowa kluczowe: ciągłe procesy fraktalne, waga filtru Kołmogorowa-Wienera, wielomiany Czybyszewa pierwszego rodzaju

\section{Introduction}

Nowadays fractal processes are widely used in different fields of knowledge, see, for example, [7] and references therein. We investigate the Kolmogorov-Wiener filter weight function for continuous fractal processes with a power-law structure function. The observation interval of the filter input signal is considered to be finite. The importance of the problem under consideration for the traffic forecast in telecommunications is stressed in [1].

As is known (see, for example, [6]), the Kolmogorov-Wiener filter weight function for continuous processes is the solution of the Wiener-Hopf integral equation, which, in fact, is the Fredholm integral equation of the first kind. In [1] it is proposed to use the Volterra integral equation rather than the Fredlolm one. The corresponding Volterra integral equation is exactly solvable (see [2]), but in the general case it may be not applicable, so we need to seek the solution of the Fredholm integral equation of the first kind.

The explicit analytical solution of the corresponding WienerHopf integral equation meets difficulties, so an approximate solution may be found. As is known [8], such a solution may be sought in the form of a truncated expansion in a complete system of functions. Such a system is often chosen as a polynomial set.

Our previous investigations were devoted to the abovementioned truncated polynomial expansion method on the basis of a polynomial set orthogonal on the observation interval without weight [3] and on the basis of the Chebyshev polynomials of the second kind [4]. The convergence behaviour of the solutions in [3] and [4] is, in fact, the same; some approximations fail, but some approximations give reliable results. Therefore, two interesting questions arise. First of all, is the behaviour of the solution convergence identical only for the sets in [3] and [4], or also for other polynomial sets? May the use of another polynomial set refine such behaviour? It is interesting then to investigate the problem under consideration on the basis of another polynomial set.

The aim of this work is to obtain the corresponding Kolmogorov-Wiener filter weight function on the basis of the Chebyshev polynomials of the first kind and to compare the results with papers $[3,4]$.

\section{Truncated polynomial expansion method}

We investigate the Kolmogorov-Wiener filter for a continuous stationary fractal process $x(t)$ with a power-law structure function $c(\tau)$ :

$$
c(\tau) \equiv\left\langle(x(t)-x(t-\tau))^{2}\right\rangle_{t}=\alpha \cdot|\tau|^{2 H}
$$

where $\alpha$ is a constant and $H \in(0,5 ; 1)$ is the Hurst exponent. The correlation function of such a process is as follows [1]:

$$
R(t)=\sigma^{2}-\frac{\alpha}{2}|t|^{2 H}
$$

where $\sigma^{2}$ is the process variance.

Let the filter input signal be observed for a time interval $t \in[0, T]$, and let us denote the time interval for which the forecast is made as $k$. Then, as is known, the KolmogorovWiener filter weight function $h(\tau)$ obeys the Wiener-Hopf integral equation

$$
R(t+k)=\int_{0}^{T} d \tau h(\tau) R(t-\tau)
$$

which, in fact, is the Fredholm integral equation of the first kind. In this paper we investigate the truncated polynomial expansion method based on the Chebychev polynomials of the first kind.

As is known [5], the Chebychev polynomials of the first kind are given by the expression

$$
T_{n}(x)=\sum_{k=0}^{[n / 2]} C_{n}^{2 k}\left(x^{2}-1\right)^{k} x^{n-2 k}
$$

where $[y]$ is the integer part of $y$. These polynomials obey the orthogonality property

$$
\int_{-1}^{1} \frac{T_{n}(x) T_{m}(x)}{\sqrt{1-x^{2}}} d x=A_{n} \delta_{n m}, A_{n}=\left\{\begin{array}{l}
\pi, n=0 \\
\pi / 2, n \neq 0
\end{array} .\right.
$$

As is known [8], according to (3) we need polynomials orthogonal on the interval $t \in[0, T]$ rather than on $[-1,1]$. 
Changing the variable in (5) yields

$$
\int_{0}^{T} T_{n}\left(\frac{2 y}{T}-1\right) T_{m}\left(\frac{2 y}{T}-1\right) w(y) d y=\frac{T}{2} A_{n} \delta_{m n}
$$

where

$$
w(y)=\left(1-\left(\frac{2 y}{T}-1\right)^{2}\right)^{-1 / 2} .
$$

So the polynomials

$$
S_{n}(t)=T_{n}\left(\frac{2 t}{T}-1\right),
$$

are orthogonal on $t \in[0, T]$ with the weight $w(y)$, and the solution $h(\tau)$ may be sought as

$$
h(\tau)=\sum_{n \geq 0} g_{n} S_{n}(\tau) .
$$

Substituting (8) into (3) one can obtain

$$
R(t+k)=\sum_{n \geq 0} g_{n} \int_{0}^{T} d \tau h(\tau) S_{n}(\tau),
$$

which after multiplying by $S_{m}(\tau)$ and integrating leads to

$$
\sum_{n} g_{n} \int_{0}^{T} \int_{0}^{T} d \tau d t S_{n}(\tau) S_{m}(t) R(t-\tau)=\int_{0}^{T} d t S_{m}(t) R(t+k)
$$

The quantities

$$
G_{n m}=\int_{0}^{T} \int_{0}^{T} d \tau d t S_{n}(\tau) S_{m}(t) R(t-\tau)
$$

are called the integral brackets, so (11) may be rewritten as

$$
\sum_{n} g_{n} G_{n m}=b_{m}
$$

where

$$
b_{m}=\int_{0}^{T} d t S_{m}(t) R(t+k)
$$

Expression (13) is an infinite set of linear algebraic equations in $g_{n}$. This set can hardly be treated, so the sum (9) should be artificially truncated:

$$
h^{[l]}(\tau)=\sum_{n=0}^{l-1} g_{n}^{[l]} S_{n}(\tau) .
$$

where $h^{[l]}(\tau)$ is the Kolmogorov-Wiener filter weight function in the $l$-polynomial approximation and $g_{n}^{[l]}$ are the corresponding coefficients multiplying the polynomials. These coefficients are the solutions of the following set of linear algebraic equations:

$$
\sum_{n=0}^{l-1} g_{n}^{[l]} G_{n m}=b_{m} \text {. }
$$

So one should obtain the values of the coefficients $g_{n}^{[l]}$ from (16) and substitute them into (15) to obtain the KolmogorovWiener filter weight function in the $l$-polynomial approximation.

It should be explained why the Chebyshev polynomials of the first kind are convenient for the problem under consideration. On the basis of (4), (8), (12) and the fact that the correlation function $R(t)$ is an even one, it can be shown that

$$
G_{n m}=0 \text { if } m, n \text { are of different parity }
$$

Also, on the basis of the fact that $R(t)$ is an even function, from (12) it is evident that

$$
G_{n m}=G_{m n}
$$

The calculation of the integral brackets takes the most part of the computing time. On the basis of (17) and (18) it can be seen that $G_{n m}$ should be computed by a straightforward calculation only for $n \geq m$ and $n, m$ of the same parity. This fact significantly reduces the computing time.

\section{Investigation of the method convergence}

This section is devoted to the investigation of the convergence behavior of the obtained solutions. First of all, as is known (see, for example, [9]), the convergence is guaranteed if the kernel of an integral equation is a positively defined function. In our case $R(t)$ is not a positively defined function, so the method convergence is not guaranteed.

In order to check the obtained solutions for different numbers of polynomials, we calculate the weight function on the basis of the Wolfram Mathematica 11.0 package and compare left-hand and right-hand sides of eq. (3) with each other.

In other words, the functions

$$
\operatorname{Left}(t)=\sum_{n=0}^{l-1} g_{n}^{[l]} \int_{0}^{T} d \tau S_{n}(\tau) R(t-\tau)
$$

and

$$
\operatorname{Right}(t)=R(t+k)
$$

are numerically compared with each other, the coefficients $g_{n}^{[l]}$ are calculated on the basis of (16). It should be stressed that the substitution of (2) into (19) gives

$$
\operatorname{Left}(t)=\sum_{n=0}^{l-1} g_{n}^{[l]} \int_{0}^{T} d \tau S_{n}(\tau)\left(\sigma^{2}-\frac{\alpha}{2}|t-\tau|^{2 H}\right),
$$

and on the basis of the Wolfram Mathematica package this function is treated as

$$
\begin{gathered}
\operatorname{Left}(t)=\sum_{n=0}^{l-1} g_{n}^{[l]} \int_{0}^{t} d \tau S_{n}(\tau)\left(\sigma^{2}-\frac{\alpha}{2}(t-\tau)^{2 H}\right)+ \\
+\sum_{n=0}^{l-1} g_{n}^{[l]} \int_{t}^{T} d \tau S_{n}(\tau)\left(\sigma^{2}-\frac{\alpha}{2}(\tau-t)^{2 H}\right)
\end{gathered}
$$

The following set of parameters is investigated:

$$
T=100, \sigma=1.2, H=0.8, \alpha=3 \cdot 10^{-3} \text {. }
$$

This set of parameters is also investigated in $[3,4]$. It should be stressed that the well-known inequality

$$
|R(t)| \leq R(0),
$$

holds for the set (23) on the observation interval $t \in[0, T]$.

The investigation is made up to the 18-polynomial approximation, the corresponding coefficients multiplying the polynomials in the $l$-polynomial approximation are given in Table 1. The coefficients in Table 1 are rounded off to three significant digits.

Table 1. Coefficients multiplying polynomials for the set (23)

\begin{tabular}{|c|c|}
\hline$l$ & Coefficients multiplying the polynomials \\
\hline 1 & $g_{0}^{[1]}=4,86 \cdot 10^{-3}$ \\
\hline 2 & $g_{0}^{[2]}=4,86 \cdot 10^{-3}, g_{1}^{[2]}=-2,91 \cdot 10^{-2}$ \\
\hline 3 & $g_{0}^{[3]}=-8,8 \cdot 10^{-2}, g_{1}^{[3]}=-2,91 \cdot 10^{-2}, g_{2}^{[3]}=-2,06 \cdot 10^{-1}$ \\
\hline 4 & $g_{0}^{[4]}=-8,8 \cdot 10^{-2}, g_{1}^{[4]}=-5,01 \cdot 10^{-2}, g_{2}^{[4]}=-2,06 \cdot 10^{-1}$, \\
& $g_{3}^{[4]}=-3,24 \cdot 10^{-2}$ \\
\hline 5 & $g_{0}^{[5]}=6,61 \cdot 10^{-2}, g_{1}^{[5]}=-5,01 \cdot 10^{-2}, g_{2}^{[5]}=1,36 \cdot 10^{-1}, g_{3}^{[5]}=-3,24 \cdot 10^{-2}$, \\
& $g_{4}^{[5]}=8,56 \cdot 10^{-2}$ \\
\hline 6 & $g_{0}^{[6]}=6,61 \cdot 10^{-2}, g_{1}^{[6]}=-7,19 \cdot 10^{-2}, g_{2}^{[6]}=1,36 \cdot 10^{-1}$, \\
\hline 7 & $g_{3}^{[6]}=-6,02 \cdot 10^{-2}, g_{4}^{[6]}=8,56 \cdot 10^{-2}, g_{5}^{[6]}=-3,28 \cdot 10^{-2}$ \\
\hline 8 & $g_{0}^{[7]}=6,68 \cdot 10^{-2}, g_{1}^{[7]}=-7,19 \cdot 10^{-2}, g_{2}^{[7]}=1,39 \cdot 10^{-1}$, \\
& $g_{0}^{[8]}=6,68 \cdot 10^{-2}, g_{1}^{[8]}=-9,51 \cdot 10^{-2}, g_{2}^{[8]}=1,39 \cdot 10^{-1}, g_{3}^{[8]}=-8,71 \cdot 10^{-2}$, \\
\hline & $g_{4}^{[8]}=1,15 \cdot 10^{-1}, g_{5}^{[8]}=-6,59 \cdot 10^{-2}, g_{6}^{[8]}=6,11 \cdot 10^{-2}, g_{7}^{[8]}=-3,27 \cdot 10^{-2}$ \\
\hline 9 & $g_{0}^{[9]}=8,02 \cdot 10^{-2}, g_{1}^{[9]}=-9,51 \cdot 10^{-2}, g_{2}^{[9]}=1,64 \cdot 10^{-1}$, \\
& $g_{3}^{[9]}=-8,71 \cdot 10^{-2}, g_{4}^{[9]}=1,49 \cdot 10^{-1}, g_{5}^{[9]}=-6,59 \cdot 10^{-2}, g_{6}^{[9]}=1,11 \cdot 10^{-1}$, \\
& $g_{7}^{[9]}=-3,27 \cdot 10^{-2}, g_{8}^{[9]}=5,37 \cdot 10^{-2}$ \\
\hline
\end{tabular}


Table 1 (cont.). Coefficients multiplying polynomials for the set (23)

\begin{tabular}{|c|c|}
\hline$l$ & Coefficients multiplying the polynomials \\
\hline 10 & $\begin{array}{c}g_{0}^{[10]}=8,02 \cdot 10^{-2}, g_{1}^{[10]}=-1,20 \cdot 10^{-1}, g_{2}^{[10]}=1,64 \cdot 10^{-1}, \\
g_{3}^{[10]}=-1,15 \cdot 10^{-1}, g_{4}^{[10]}=1,49 \cdot 10^{-1}, g_{5}^{[10]}=-9,86 \cdot 10^{-2}, g_{6}^{[10]}=1,11 \cdot 10^{-1}, \\
g_{7}^{[10]}=-6,97 \cdot 10^{-2}, g_{8}^{[10]}=5,37 \cdot 10^{-2}, g_{9}^{[10]}=-3,26 \cdot 10^{-2}\end{array}$ \\
\hline 11 & $\begin{array}{c}g_{0}^{[11]}=9,53 \cdot 10^{-2}, g_{1}^{[11]}=-1,20 \cdot 10^{-1}, g_{2}^{[11]}=1,94 \cdot 10^{-1} \\
g_{3}^{[11]}=-1,15 \cdot 10^{-1}, \quad g_{4}^{[11]}=1,86 \cdot 10^{-1}, g_{5}^{[1] 1]}=-9,86 \cdot 10^{-2} \\
g_{6}^{[11]}=1,57 \cdot 10^{-1}, \quad g_{7}^{[11]}=-6,97 \cdot 10^{-2}, g_{8}^{[11]}=1,09 \cdot 10^{-1} \\
g_{9}^{[11]}=-3,26 \cdot 10^{-2}, g_{10}^{[11]}=5,03 \cdot 10^{-2}\end{array}$ \\
\hline 12 & $\begin{array}{c}g_{0}^{[12]}=9,53 \cdot 10^{-2}, g_{1}^{[12]}=-1,47 \cdot 10^{-1}, \quad g_{2}^{[12]}=1,94 \cdot 10^{-1}, \\
g_{3}^{[12]}=-1,44 \cdot 10^{-1}, \quad g_{4}^{[12]}=1,86 \cdot 10^{-1}, \quad g_{5}^{[1] 2]}=-1,32 \cdot 10^{-1}, \\
g_{6}^{[12]}=1,57 \cdot 10^{-1}, \quad g_{7}^{[12]}=-1,07 \cdot 10^{-1}, \quad g_{8}^{[12]}=1,09 \cdot 10^{-1}, \\
g_{9}^{[12]}=-7,24 \cdot 10^{-2}, g_{10}^{[12]}=5,03 \cdot 10^{-2}, \quad g_{11}^{[12]}=-3,25 \cdot 10^{-2}\end{array}$ \\
\hline 13 & $\begin{array}{c}g_{0}^{[13]}=1,13 \cdot 10^{-1}, \quad g_{1}^{[13]}=-1,47 \cdot 10^{-1}, \quad g_{2}^{[13]}=2,29 \cdot 10^{-1}, \\
g_{3}^{[13]}=-1,44 \cdot 10^{-1}, \quad g_{4}^{[13]}=2,25 \cdot 10^{-1}, \quad g_{5}^{[13]}=-1,32 \cdot 10^{-1}, \\
g_{6}^{[13]}=2,03 \cdot 10^{-1}, \quad g_{7}^{[13]}=-1,07 \cdot 10^{-1}, \quad g_{8}^{[13]}=1,64 \cdot 10^{-1}, \\
g_{9}^{[13]}=-7,24 \cdot 10^{-2}, \quad g_{10}^{[13]}=1,09 \cdot 10^{-1}, \quad g_{11}^{[13]}=-3,25 \cdot 10^{-2}, \\
g_{12}^{[13]}=4,82 \cdot 10^{-2}\end{array}$ \\
\hline 14 & $\begin{array}{c}g_{0}^{[14]}=1,13 \cdot 10^{-1}, \quad g_{1}^{[14]}=-1,76 \cdot 10^{-1}, g_{2}^{[14]}=2,29 \cdot 10^{-1}, \\
g_{3}^{[14]}=-1,74 \cdot 10^{-1}, g_{4}^{[14]}=2,25 \cdot 10^{-1}, g_{5}^{[14]}=-1,65 \cdot 10^{-1}, \\
g_{6}^{[14]}=2,03 \cdot 10^{-1}, g_{7}^{[14]}=-1,45 \cdot 10^{-1}, g_{8}^{[14]}=1,64 \cdot 10^{-1}, \\
g_{9}^{[14]}=-1,14 \cdot 10^{-1}, g_{10}^{[14]}=1,09 \cdot 10^{-1}, g_{11}^{[14]}=-7,44 \cdot 10^{-2}, \\
g_{12}^{[14]}=4,82 \cdot 10^{-2}, g_{13}^{[14]}=-3,24 \cdot 10^{-2} .\end{array}$ \\
\hline 15 & $\begin{array}{l}g_{0}^{[15]}=1,31 \cdot 10^{-1}, g_{1}^{[15]}=-1,76 \cdot 10^{-1}, g_{2}^{[15]}=2,68 \cdot 10^{-1}, \\
g_{3}^{[15]}=-1,74 \cdot 10^{-1}, g_{4}^{[15]}=2,66 \cdot 10^{-1}, \quad g_{5}^{[15]}=-1,65 \cdot 10^{-1}, \\
g_{6}^{[15]}=2,50 \cdot 10^{-1}, g_{7}^{[15]}=-1,45 \cdot 10^{-1}, g_{8}^{[15]}=2,18 \cdot 10^{-1}, \\
g_{9}^{[15]}=-1,14 \cdot 10^{-1}, g_{10}^{[15]}=1,69 \cdot 10^{-1}, g_{11}^{[15]}=-7,44 \cdot 10^{-2}, \\
g_{12}^{[15]}=1,09 \cdot 10^{-1}, g_{13}^{[15]}=-3,24 \cdot 10^{-2}, \quad g_{14}^{[15]}=4,69 \cdot 10^{-2} .\end{array}$ \\
\hline 16 & $\begin{array}{c}g_{0}^{[16]}=1,31 \cdot 10^{-1}, g_{1}^{[16]}=-2,07 \cdot 10^{-1}, g_{2}^{[16]}=2,68 \cdot 10^{-1}, \\
g_{3}^{[16]}=-2,07 \cdot 10^{-1}, g_{4}^{[16]}=2,66 \cdot 10^{-1}, g_{5}^{[16]}=-2,00 \cdot 10^{-1}, \\
g_{6}^{[16]}=2,50 \cdot 10^{-1}, g_{7}^{[16]}=-1,84 \cdot 10^{-1}, g_{8}^{[16]}=2,18 \cdot 10^{-1}, \\
g_{9}^{[16]}=-1,57 \cdot 10^{-1}, \quad g_{10}^{[16]}=1,69 \cdot 10^{-1}, \quad g_{11}^{[16]}=-1,20 \cdot 10^{-1}, \\
g_{12}^{[16]}=1,09 \cdot 10^{-1}, g_{13}^{[16]}=-7,56 \cdot 10^{-2}, g_{14}^{[16]}=4,69 \cdot 10^{-2}, \\
g_{15}^{[16]}=-3,22 \cdot 10^{-2}\end{array}$ \\
\hline 17 & $\begin{array}{c}g_{0}^{[17]}=1,52 \cdot 10^{-1}, g_{1}^{[17]}=-2,07 \cdot 10^{-1}, g_{2}^{[17]}=3,09 \cdot 10^{-1}, \\
g_{3}^{[17]}=-2,07 \cdot 10^{-1}, g_{4}^{[17]}=3,10 \cdot 10^{-1}, g_{5}^{[17]}=-2,00 \cdot 10^{-1} \\
\quad g_{6}^{[17]}=2,99 \cdot 10^{-1}, g_{7}^{[17]}=-1,84 \cdot 10^{-1} \\
g_{8}^{[177]}=2,72 \cdot 10^{-1}, g_{9}^{[17]}=-1,57 \cdot 10^{-1}, g_{10}^{[117]}=2,30 \cdot 10^{-1} \\
g_{11}^{[17]}=-1,20 \cdot 10^{-1}, g_{12}^{[17]]}=1,74 \cdot 10^{-1}, g_{13}^{[17]}=-7,56 \cdot 10^{-2} \\
g_{14}^{[17]}=1,09 \cdot 10^{-1}, g_{15}^{[17]}=-3,22 \cdot 10^{-2}, g_{16}^{[17]}=4,59 \cdot 10^{-2}\end{array}$ \\
\hline 18 & $\begin{array}{c}g_{0}^{[18]}=1,52 \cdot 10^{-1}, \quad g_{1}^{[18]}=-2,40 \cdot 10^{-1}, \quad g_{2}^{[18]}=3,09 \cdot 10^{-1}, \\
g_{3}^{[18]}=-2,41 \cdot 10^{-1}, \quad g_{4}^{[18]}=3,10 \cdot 10^{-1}, \quad g_{5}^{[18]}=-2,36 \cdot 10^{-1}, \\
g_{6}^{[18]}=2,99 \cdot 10^{-1}, \quad g_{7}^{[18]}=-2,23 \cdot 10^{-1}, g_{8}^{[18]}=2,72 \cdot 10^{-1}, \\
g_{9}^{[18]}=-2,00 \cdot 10^{-1}, \quad g_{10}^{[18]}=2,30 \cdot 10^{-1}, \quad g_{11}^{[18]}=-1,66 \cdot 10^{-1}, \\
g_{12}^{[18]}=1,74 \cdot 10^{-1}, \quad g_{13}^{[18]}=-1,24 \cdot 10^{-1}, \quad g_{14}^{[188]}=1,09 \cdot 10^{-1}, \\
g_{15}^{[18]}=-7,70 \cdot 10^{-2}, \quad g_{16}^{[18]}=4,59 \cdot 10^{-2}, \quad g_{17}^{[18]}=-3,21 \cdot 10^{-2}\end{array}$ \\
\hline
\end{tabular}

The obtained comparison of $\operatorname{Left}(t)$ and $\operatorname{Right}(t)$ is illustrated on the following graphs. The function $\operatorname{Right}(t)$ is shown as a solid line, and the functions Left $(t)$ are shown as dotted lines.

The corresponding comparison for the one-polynomial approximation is shown in Fig. 1. As can be seen, the onepolynomial approximation is not accurate enough.

For the two-polynomial approximation we have (see Fig. 2).

As can be seen, the two-polynomial approximation is rather accurate: the functions $\operatorname{Left}(t)$ and $\operatorname{Right}(t)$ are rather close to each other.

The graphs for the three-polynomial and the four-polynomial approximations are approximately the same. As can be seen, they are less accurate than the two-polynomial one, but more accurate than the one-polynomial one.

As can also be seen from Fig. 2 and Fig. 3, the approximation accuracy may not increase with the number of polynomials. Such behavior of the approximations may take place because the correlation function $R(t)$, which is the kernel of the integral equation (3), is not positively defined.

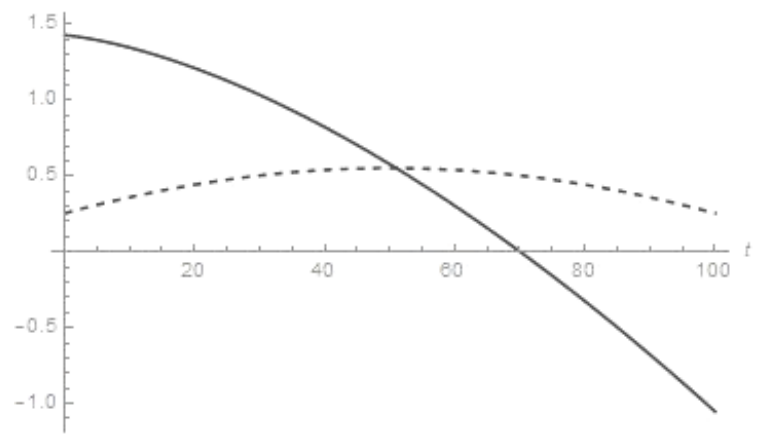

Fig. 1. Comparison of Left $(t)$ and Right $(t)$ for the one-polynomial approximation for parameters $(23)$

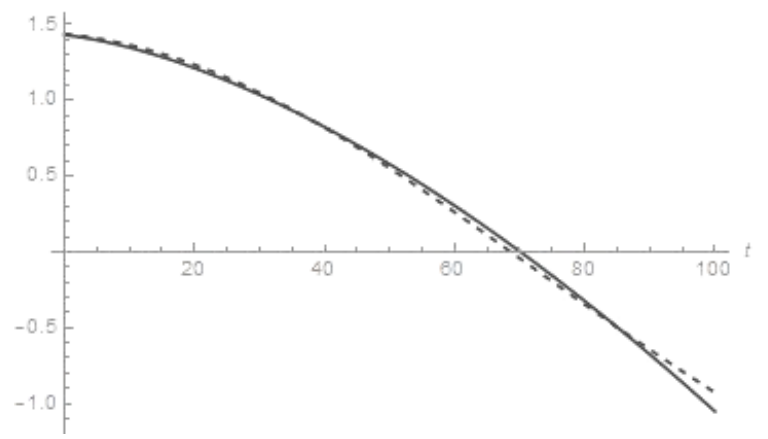

Fig. 2. Comparison of Left(t) and Right( $t)$ for the two-polynomial approximation for parameters $(23)$

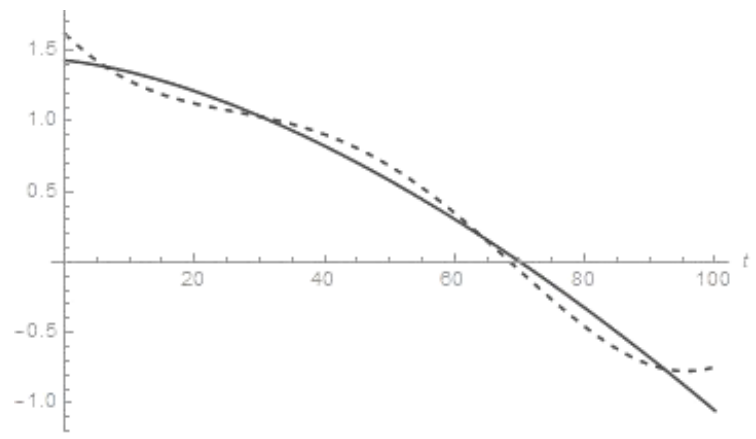

Fig. 3. Comparison of Left(t) and Right(t) for the three-polynomial approximation for parameters (23)

As can be seen from Fig. 4, the five-polynomial approximation is accurate: the graphs of $\operatorname{Left}(t)$ and $\operatorname{Right}(t)$ almost coincide.

The investigation of the number of polynomials from 5 to 8 shows that the accuracy of the corresponding approximations increases with the number of polynomials. For example, the comparison for the eight-polynomial approximation is given in Fig. 5.

As can be seen from Fig. 4 and Fig. 5, the eight-polynomial approximation is more accurate than the five-polynomial one.

But, unfortunately, the investigation of the numbers of polynomials from 9 to 15 shows that the corresponding approximations completely fail. Such behavior of the solutions is rather strange. In our opinion, it may be explained as follows. The convergence of the method is not guaranteed because the kernel of the integral equation (3) is not a positively defined function. So, not only may the accuracy not increase with the number of polynomials, but some approximations may also completely fail. 


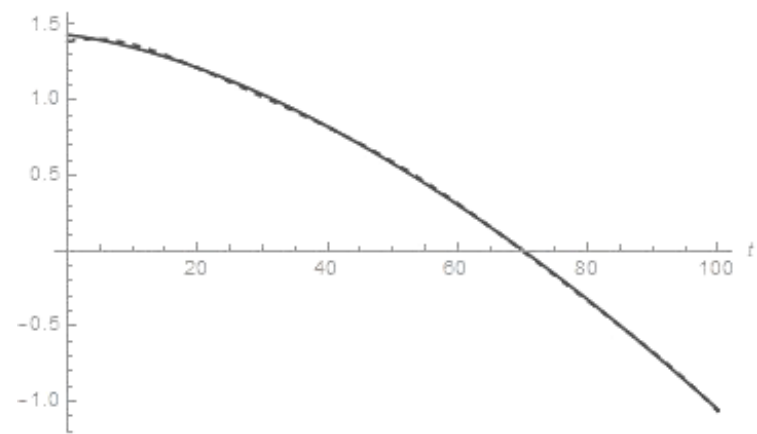

Fig. 4. Comparison of Left $(t)$ and Right( $(t)$ for the five-polynomial approximation for parameters (23)

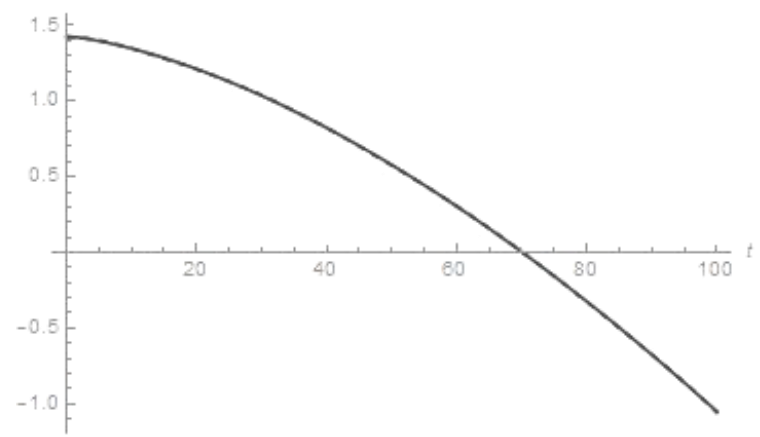

Fig. 5. Comparison of Left(t) and Right(t) for the eight-polynomial approximation for parameters (23)

But the investigation of the number of polynomials from 16 to 18 shows that the corresponding approximations give almost ideal results. Approximations of more than 18 polynomials are not investigated because the "unphysical ripple" takes place on the graphs in such a case. In our opinion, such a situation occurs because Wolfram Mathematica has not enough recourses to build corresponding graphs adequately.

The same behavior of $\operatorname{Left}(t)$ and $\operatorname{Right}(t)$ is also observed for other polynomial sets in papers [3,4].

The following parameter sets are also investigated for the same reason as the set (23):

and

$$
T=10, \sigma=1.2, H=0.8, \alpha=10^{-1} .
$$

$$
T=1000, \sigma=1.2, H=0.8, \alpha=8 \cdot 10^{-5} .
$$

It is obtained that the behavior of $\operatorname{Left}(t)$ and $\operatorname{Right}(t)$ for these sets is also the same as for the other polynomial sets described in $[3,4]$.

\section{Conclusion}

This paper is devoted to the investigation of the KolmogorovWiener weight function for continuous fractal processes with a power-law structure function. As an exact analytical solution to the corresponding integral equation (2) can hardly be found, we use the truncated polynomial expansion method in order to obtain an approximate solution to this equation. In this paper the weight function is expanded in a truncated series of the Chebyshev polynomials of the first kind.

It is shown that the accuracy of polynomial approximations may not increase with the number of polynomials. Moreover, some of the approximations may totally fail. In our opinion, it takes place because the kernel of the integral equation (2) is not a positively defined function.

However, it is shown that some approximations give reliable results, so the method under consideration may lead to good results. It should be stressed, however, that each approximation should be checked numerically.
The results are compared with the corresponding results of papers $[3,4]$ where other polynomial sets were used. In paper [3] the same problem is investigated on the basis of polynomials orthogonal on the observation interval without weight. In paper [4] the corresponding investigation is made on the basis of the Chebyshev polynomials of the second kind. It is shown that the convergence behavior of the solutions is the same for all the above-mentioned polynomial sets. So, the hypothesis may be made that the convergence behavior of the solutions is independent of the polynomial set used in the framework of the truncated polynomial expansion method.

The obtained results may be applied to the investigation of the fractal process forecast in different systems of practical interest, for example, for telecommunication traffic forecast.

\section{References}

[1] Bagmanov V. Kh., Komissarov A. M., Sultanov A. Kh.: Teletraffic forecast on the basis of fractal fliters. Bulletin of Ufa State Aviation Technical University 9(6(24))/2007, 217-222 (in Russian).

[2] Gorev V. N., Gusev A. Yu., Korniienko V. I.: On the analytical solution of Volterra integral equation for investigation of fractal processes. Radio Electronics, Computer Science, Control 4/2018, 42-50.

[3] Gorev V. N., Gusev A. Yu., Korniienko V. I.: Polynomial solutions for the Kolmogorov-Wiener filter weight function for fractal processes. Radio Electronics, Computer Science, Control 2/2019, 44-52.

[4] Gorev V. N., Gusev A. Yu., Korniienko V. I.: Investigation of the KolmogorovWiener filter for treatment of fractal processes on the basis of the Chebyshev polynomials of the second kind, CEUR Workshop Proceedings 2353/2019, 596606.

[5] Gradshteyn I. S., Ryzhik I. M.: Table of Integrals, Series, and Products, Eighth edition, Zwillinger D., Moll V. (Ed.) Elsevier, Amsterdam 2015

[6] Miller S., Childers D.: Probability and Random Processes With Applications to Signal Processing and Communications, Second edition. Elseiver, Amsterdam 2012

[7] Pipiras V., Taqqu M.: Long-Range Dependence and Self-Similarity. Cambridge University Press, 2017

[8] Polyanin A. D., Manzhirov A. V.: Handbook of the integral equations., Second edition. Boca Raton, Chapman \& Hall/CRC Press 2008.

[9] Ziman J. M.: Electrons and Phonons. The Theory of Transport Phenomena in Solids. Oxford University Press, 2001

\section{Ph.D. Vyacheslav Gorev \\ e-mail: lordjainor@gmail.com \\ In 2012 graduated from the Department of Theoretical Physics of Oles Honchar Dnipro National University. In 2016 defended a Ph.D. thesis in theoretical physics. Since 2017 has been working at the Department of Information Security and Telecommunications of Dnipro University of Technology.}

http://orcid.org/0000-0002-9528-9497

\section{Prof. Alexander Gusev}

e-mail: gusev1950@ukr.net

In 1972 graduated from the Department of Automation and Telemechanics of the Novosibirsk Electrotechnical Institute. From 1972 worked in the Siberian branch of the USSR Academy of Sciences. In 1982 defended a Ph.D thesis. From 1983 worked at the Dnepropetrovsk Scientific Institute of Automation. Since 2005 works as a professor of Dnipro University of Technology.

http://orcid.org/0000-0002-0548-728X

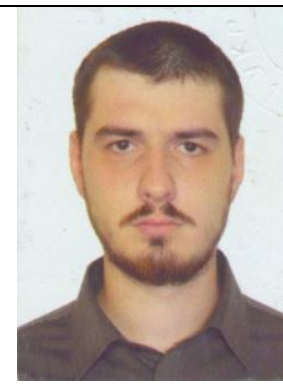

Prof. Valerii Korniienko

e-mail: vikor7@ukr.net

Doctor of Engineering Science (2010), Professor (2011). In 1979 graduated from Dnipropetrovsk Mining Institute in the specialty of "Automation and Telemechanics". He is the Head of the Department of Information Security and Telecommunication since 2016. He has 130 scientific publications. His inventions were introduced in the Ukrainian-Russian space vehicle 'Ocean-O'.

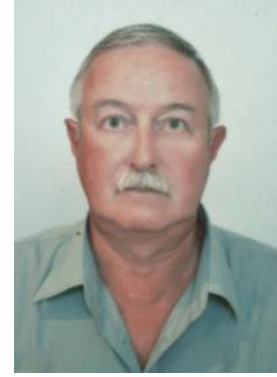

